\title{
Material Inovatif Ramah Lingkungan: Pemanfaatan Komposit Abu Serabut Kelapa dan Fly Ash pada Pasta Semen
}

\author{
Ridho Bayuaji, Riky Wahyu Kurniawan, Abdul Karim Yasin, \\ Herta Ahsani Takwim Fatoni, Faizah Maulidya Afifah Lutfi \\ Program Studi Diploma Teknik Sipil FTSP ITS, Surabaya \\ Email:bayuaji@ce.its.ac.id
}

\begin{abstract}
Indonesia is famous for its local materials wealth. However, these material have not been fully utilized for concrete technology. It is well known that concrete is the backbone material in the construction of infrastructure. The main ingredient of concrete is cement; a material strongly criticized by environmentalists for the manufacture of cement produces significant $\mathrm{CO}_{2}$. On the other hand, in the cement material contains material that can be used as material innovations, $\mathrm{CaOH}$. $\mathrm{CaOH}$ can react with pozzolan materials and produce strongth and durable products, CSH. Pozzolan materials used in this study were coconut fibers ash and fly ash. These materials were used as composite pozzolan to get strength of cement paste at 3 and 7 days using SNI - 031974-1990. This study concluded that the optimum composition of coconut fiber ash and fly ash to substitute $30 \%$ of cement was $25 \%$ of coconut fibers ash and $5 \%$ fly ash.
\end{abstract}

Keyword: coconut fiber ash, fly ash, pozzolan, compressive strength, cement paste.

Abstrak

Indonesia memiliki kekayaan material lokal yang berlimpah dan belum dimanfaatkan secara maksimal pada teknologi beton. Beton adalah material utama di bidang konstruksi. Konsep utama material beton tersusun dari bahan pengikat dan pengisi. Semen, bahan pengikat utama beton yang disorot oleh pemerhati lingkungan sebagai salah industri yang tidak ramah lingkungan oleh karena pembakaran bahan baku semen di kiln memerlukan energi sampai dengan suhu 1450o $\mathrm{C}$ dan keluarannya adalah limbah udara $\mathrm{CO}_{2}$. Di sisi lain, senyawa kandungan semen yang dapat dimanfaatkan dalam inovasi adalah Kalsium Hidroksida $(\mathrm{CaOH})$, senyawa ini akan bereaksi dengan material pozzolan dan menghasilkan produk kekuatan dan keawetan tambahan pada beton, Kalsium Silikat Hidrat (C-S-H). Material pozzolan yang akan diteliti adalah abu serabut kelapa dan fly ash sebagai bahan pozzolan komposit pada kekuatan pasta semen dengan standar SNI-03-1974-1990 pada umur hidrasi 3 dan 7 hari. Hasil penelitian ini memberi kesimpulan bahwa komposisi optimum komposit limbah sabut kelapa dan fly ash berhasil mensubtitusi $30 \%$ semen dengan komposisi: $25 \%$ abu serabut kelapa dan $5 \%$ fly ash.

Kata kunci: abu serabut kelapa, fly ash, pozzolan, kuat tekan, pasta semen.

\section{Pendahuluan}

Indonesia memiliki kekayaan material lokal yang berlimpah dan belum dimanfaatkan secara maksimal pada teknologi beton. Beton adalah material utama di bidang konstruksi. Konsep utama material beton tersusun dari bahan pengikat dan pengisi. Semen, bahan pengikat utama beton yang disorot oleh pemerhati lingkungan sebagai salah industri yang tidak ramah lingku- ngan oleh karena pembakaran bahan baku semen di klinker memerlukan energi dengan suhu sampai $1450^{\circ} \mathrm{C}$ dan keluarannya adalah limbah udara $\mathrm{CO}_{2}$.

Fakta yang perlu mendapat perhatian serius untuk isu lingkungan bahwa dalam produksi setiap satu ton semen menghasilkan satu ton emisi $\mathrm{CO}_{2}$ 
dilepaskan ke udara bebas (Van Oss and Padovani 2002).

Di lain sisi, Indonesia merupakan salah satu negara penghasil bahan pangan terbesar, seperti padi, jagung, tebu dan kelapa. Indonesia memiliki lahan untuk kelapa terluas di dunia dengan wilayah mendekati 3,74 ha (Kementan 2005). Kelapa merupakan salah satu komoditas kebutuhan manusia yang nilai konsumsinya tinggi, berbagai olahan dapat dibuat dari buah kelapa.

Dari pengujian abu serabut kelapa (ASK) yang dilakukan Balai Besar Teknik Kesehatan Lingkungan (BBTKL), diperoleh komposisi senyawa Silika $\left(\mathrm{SiO}_{2}\right)$ sejumlah 67,55\%. Komposisi ini membuktikan bahwa ASK mempunyai potensi untuk dikolaborasikan dengan fly ash (FA) sebagai supplementary cementitious material (SCM). Penelitian sebelumnya yang telah memanfaatkan material lokal berkarakter pozzolan pada beton sebagai contoh: abu sekam padi (Bayuaji and Nuruddin 2014, Bayuaji 2015), abu lumpur lapindo (Nuruddin and Bayuaji 2010), abu gunung bromo (Bayuaji, 2011) dan material lainnya.

Inovasi ini berdampak mengurangi emisi gas $\mathrm{CO}_{2}$ pada proses pembuatan semen. Efek positif pada teknologi beton meliputi tetap memenuhi standar kekuatan, ekonomis dan ramah lingkungan.

Penelitian ini akan membahas pengaruh pemanfaatan komposit ASK dan FA dalam mereduksi pengunaan semen.

\subsection{Semen}

Senyawa oksida utama yang terdapat pada semen portland dari uji XRF meliputi: $\mathrm{CaO}(60-70 \%), \mathrm{SiO}_{2}$ $22 \%), \mathrm{Al}_{2} \mathrm{O}_{3}$ (4-6\%) $\mathrm{Fe}_{2} \mathrm{O}_{3}$ (2-4\%). Klinker terdiri dari sekitar $95 \%$ oksidaoksida tersebut dan 5\% sisanya adalah $\mathrm{MgO}, \mathrm{K}_{2} \mathrm{O}, \mathrm{Na}_{2} \mathrm{O}, \mathrm{TiO}, \mathrm{Mn}_{2} \mathrm{O}_{3}, \mathrm{SO}_{3}$. Oksida-oksida utama tersebut menyusun mineral utama dari klinker. Selain senyawa oksida, Tabel 1 mencantumkan senyawa utama penyusun semen.

Tabel 1. Senyawa utama penyusun semen

\begin{tabular}{cccc}
$\begin{array}{c}\text { Nama } \\
\text { Oksida }\end{array}$ & Rumus Kimia & $\begin{array}{c}\text { Senyawa } \\
\text { Penyusun }\end{array}$ & $\begin{array}{c}\text { Kadar } \\
(\%)\end{array}$ \\
\hline Alit & $3 \mathrm{CaO} . \mathrm{SiO}_{2}$ & $\mathrm{C}_{3} \mathrm{~S}$ & $55-56$ \\
$\begin{array}{c}\text { Belit } \\
\text { Aluminat } \\
\text { Ferit } \\
\text { atau }\end{array}$ & $3 \mathrm{CaO} \cdot \mathrm{Al}_{2} \mathrm{O}_{3}$ & $\mathrm{C} 3 \mathrm{~A}$ & $8-14$ \\
Milerit & $4 \mathrm{CaO}_{2} \mathrm{Al}_{2} \mathrm{O}_{3} \mathrm{Fe}_{2} \mathrm{O}_{3}$ & $\mathrm{C} 4 \mathrm{AF}$ & $8-12$ \\
\hline
\end{tabular}

Dampak yang ditimbulkan akibat produksi klinker semen portland biasa dapat dikurangi salah satunya dengan cara menggunakan semen komposit yang sebagian klinkernya digantikan SCM.

\subsection{Fly Ash}

Fly ash adalah produk residu dari pembakaran batu bara, yang dikumpulkan dengan metode elektrostatis atau pengendapan mekanik. Fly ash mempunyai morfologi yang bulat sehingga memudahkan pengikatan hidrasi dengan semen.

Kandungan reaktif $\mathrm{SiO}_{2}$ dan $\mathrm{Al}_{2} \mathrm{O}_{3}$ dalam material pozzolan dapat bereaksi hidrasi dengan kalsium hidroksida yang disediakan oleh hidrasi OPC membentuk bahan perekat yang sama dengan 
hasil hidrasi OPC. Reaksi pozzolanik secara kualitatif disebut aluminosilikat (AS).

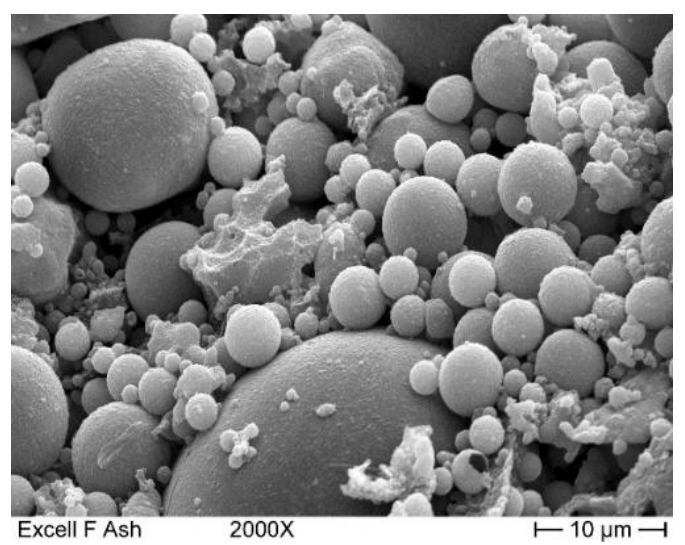

Gambar 1. Fly Ash pada pembesaran 2000 kali

Fly ash, bahan tambahan mineral yang bersifat pozzolan. Standar material internasional (ASTM-C618-03 2003) mengklasifikasi mutu pozzolan dibagi menjadi 3 (tiga) kelas yang mempunyai sifat sesuai Tabel 2.

Tabel 2. Tipe Fly Ash

\begin{tabular}{lccc}
\hline \multirow{2}{*}{ Kandungan } & \multicolumn{3}{c}{ Fly ash Tipe } \\
\cline { 2 - 4 } & $\mathrm{N}$ & $\mathrm{C}$ & $\mathrm{F}$ \\
\hline $\mathrm{SiO}_{2}+\mathrm{Al}_{2} \mathrm{O}_{3}+\mathrm{Fe}_{2} \mathrm{O}_{3}$ (\%min) & 70 & 50 & 70 \\
$\mathrm{SO}_{3}(\%$ maks) & 4 & 5 & 5 \\
$\mathrm{Na}_{2} \mathrm{O}(\%$ maks) & 1,5 & 1,5 & 1,5 \\
$\mathrm{Kadar} \mathrm{Kelembaban} \mathrm{( \% maks)}_{\text {Lay }}$ & 3 & 3 & 3 \\
Loss Ignition (\%maks) & 10 & 6 & 12 \\
\hline
\end{tabular}

\subsection{Abu Serabut Kelapa}

Penggunaan abu serbuk silika dalam hidrasi OPC telah menjadi fokus diskusi yang menarik beberapa tahun akhir ini. Penggunaan silika sebagai material subtitusi semen memberi pengaruh kuat tekan lebih baik, ekonomis dan ramah lingkungan. Permukaan silika akan bertindak sebagai tempat nukleasi atau reaksi awal pembentukan $\mathrm{CH}$ dan
$\mathrm{CSH}$, yang akan mempercepat hidrasi dari klinker semen (terutama $\mathrm{C}_{3} \mathrm{~S}$ ) sehingga meningkatkan kuat tekan pada umur awal. Efek dari nukleasi terhadap kekuatan beton meningkat sesuai kehalusan dan luas permukaan dari bahan silika tersebut (Neville 2010).

\section{Metodologi}

Penelitian ini dilakukan dengan metodologi eksperimen di laboratorium uji material Prodi Diploma Teknik Sipil FTSP ITS.

Salah satu material penyusun pasta semen adalah FA yang diperoleh dari pembakaran PLTU Paiton dengan hasil uji fisik dan kimia. Data uji fisik dan kimia ditampilkan pada Tabel 3

Tabel 3. Sifat kimia dan sifat fisika FA

\begin{tabular}{lc}
\hline \multicolumn{2}{c}{ Sifat Kimia } \\
\hline Silica $\left(\mathrm{SiO}_{2}\right) \%$ & 54,5 \\
Alumina $\left(\mathrm{Al}_{2} \mathrm{O}_{3}\right) \%$ & 23,0 \\
Oksida $\mathrm{Besi}\left(\mathrm{Fe}_{2} \mathrm{O}_{3}\right) \%$ & 5,3 \\
Kapur $(\mathrm{CaO}) \%$ & 9,5 \\
Oksida Magnesium $(\mathrm{MgO}) \%$ & 2,0 \\
Sulphuric Anyhydrate $\left(\mathrm{SO}_{3}\right) \%$ & 0,5 \\
Lain-lain \% & 5,2 \\
\hline \multicolumn{1}{c}{ Sifat Fisika } \\
\hline Luas Permukaan $\left(\mathrm{m}^{2} / \mathrm{kg}\right)$ & 287 \\
Berat Jenis $\left(\right.$ gram $\left./ \mathrm{cm}^{3}\right)$ & 2,49 \\
\hline
\end{tabular}

Semen yang digunakan adalah semen Gresik tipe I dengan maksud mengetahui perbedaan perkembangan hidrasi pada kondisi normal dibandingkan dengan penambahan pozzolan. Sifat fisik dan kimia semen diuraikan pada Tabel 3. Densiti dan luas partikel semen diketahui masing-masing 3,15 dan 359 $\mathrm{m}^{2} / \mathrm{kg}$. 
Tabel 4. Sifat Fisik dan Kimia Semen

\begin{tabular}{|c|c|c|}
\hline Parameter & $\begin{array}{c}\text { SNI 15-2049- } \\
2004\end{array}$ & Hasil Tes \\
\hline \multicolumn{3}{|l|}{ Komposisi Kimia } \\
\hline $\mathrm{Al}_{2} \mathrm{O}_{3}$ & & 6.03 \\
\hline $\mathrm{SiO}_{2}$ & & 20.65 \\
\hline $\mathrm{Fe}_{2} \mathrm{O}_{3}$ & & 3.44 \\
\hline $\mathrm{CaO}$ & & 65.96 \\
\hline $\mathrm{MgO}$ & Max 6.00 & 2.05 \\
\hline $\mathrm{SO}_{3}$ & $\operatorname{Max} 3.50$ & 2.22 \\
\hline Loss on Ignition & Max 5.00 & 3.96 \\
\hline Free Lime & & 1.09 \\
\hline Insoluble residue & & 2.37 \\
\hline \multicolumn{3}{|l|}{ Alkali } \\
\hline$\left(\mathrm{Na}_{2} \mathrm{O}+0,658 \mathrm{~K}_{2} \mathrm{O}\right)$ & & 0.38 \\
\hline \multicolumn{3}{|c|}{ Propoerti X-Ray Difraction } \\
\hline \multicolumn{3}{|c|}{ Tricalcium Silicate } \\
\hline$\left(\mathrm{C}_{3} \mathrm{~S}\right)$ & & 56.68 \\
\hline \multicolumn{3}{|l|}{ Dicalcium Silicate } \\
\hline$\left(\mathrm{C}_{2} \mathrm{~S}\right)$ & & 11.00 \\
\hline \multicolumn{3}{|l|}{ Tricalcium Aluminate } \\
\hline$(\mathrm{C} 3 \mathrm{~A})$ & & 7.72 \\
\hline \multicolumn{3}{|l|}{ Tetracalcium } \\
\hline \multicolumn{3}{|l|}{ Aluminate Ferrite } \\
\hline \multicolumn{3}{|l|}{ Properti Fisik } \\
\hline \multicolumn{3}{|l|}{ Kehalusan } \\
\hline $\begin{array}{l}\text {-Blaine specific } \\
\text { surface }\left(\mathrm{m}^{2} / \mathrm{kg}\right)\end{array}$ & $\operatorname{Min} 280$ & 359 \\
\hline \multicolumn{3}{|l|}{ Waktu setting, Vicat } \\
\hline \multicolumn{3}{|l|}{ Test: } \\
\hline - Initial set (minutes) & Min 45 & 125 \\
\hline - final set (menit) & Max 375 & 240 \\
\hline \multicolumn{3}{|l|}{ Autoclave test: } \\
\hline -Expansion (\%) & Max 0.8 & 0.10 \\
\hline \multicolumn{3}{|l|}{ Kuat Tekan: } \\
\hline-3 hari $\left(\mathrm{kg} / \mathrm{cm}^{2}\right)$ & Min 125 & 255 \\
\hline-7 hari $\left(\mathrm{kg} / \mathrm{cm}^{2}\right)$ & Min 200 & 316 \\
\hline-28 hari $\left(\mathrm{kg} / \mathrm{cm}^{2}\right)$ & Min 280 & 411 \\
\hline False set $(\%)$ & Min 50 & 77,36 \\
\hline
\end{tabular}

Sabut kelapa yang digunakan dalam penelitian ini adalah limbah kelapa dari pasar mangga dua, wonokromo, Surabaya. Dimana kelapa yang digunakan adalah kelapa tua. Selanjutnya untuk dapat digunakan dalam penelitian dilakukan pembakaran yang fungsinya untuk memperoleh kandungan silica yang tinggi didalam abu sabut kelapa, proses pembakaran dilakukan di laboratorium beton dan material Jurusan Teknik Sipil ITS Sukolilo dengan total waktu pembakaran 6 jam dan suhu maksimal $600^{\circ} \mathrm{C}$, detail proses pembakaran ditampilkan pada Gambar 2.

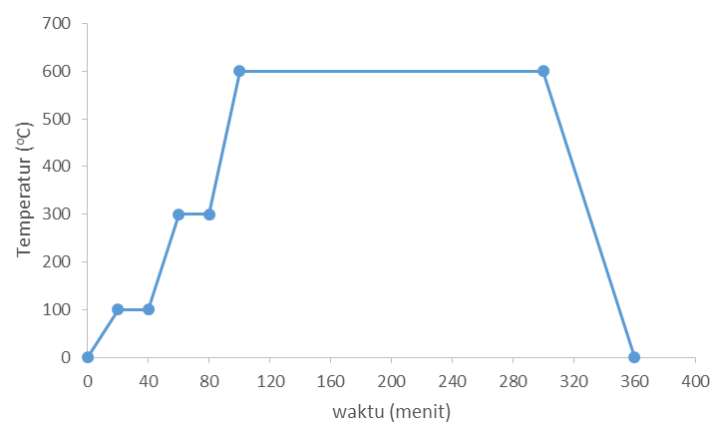

Gambar 2. Grafik hubungan waktu dan temperatur pada pembakaran serabut kelapa.

Analisa komposisi optimum penggunaan ASK dan FA sebagai bahan subtitusi komposit semen pada pasta semen dilakukan menggunakan pendekatan pengujian kuat tekan pasta dengan benda uji berupa silinder dengan diameter $2,5 \mathrm{~cm}$ dan tinggi $5 \mathrm{~cm}$ dan standar SNI-03-1974-1990 pada umur hidrasi 3 dan 7 hari.

Presentase semen tipe I jenis OPC, ASK dan FA sebagai bahan pengkat dijadikan beberapa level variabel. Kadar semen direduksi dari 0\% hingga 70\% dengan rentang $10 \%$. Pada setiap kadar reduksi semen, presentase ASK dan FA diuji seluruh variasinya dengan rentang 10\%. diperlukan 13 benda uji untuk mencapai akurasi tinggi. Perbandingan air:bahan pengikat (w/c) dijadikan tetap pada nilai 0,3 sebagai variabel control adalah semen OPC $100 \%$. Hasil uji berupa kuat tekan umur 1 hari, 3 hari dan 7 hari sebagai variabel respon. Pengujian kuat tekan dilakukan menggunakan Universal Testing $M a$ chine (UTM) di Laboratorium Uji Material Prodi Diploma Teknik Sipil ITS Surabaya. 
Tabel 5. Variasi Benda Uji

\begin{tabular}{|c|c|c|c|c|c|c|c|}
\hline \multirow[b]{2}{*}{$\begin{array}{l}\mathrm{N} \\
\mathrm{o} .\end{array}$} & \multicolumn{3}{|c|}{ Kebutuhan (\%) } & \multicolumn{4}{|c|}{ Kebutuhan Massa (gram) } \\
\hline & $\begin{array}{c}\mathrm{Se} \\
\mathrm{me} \\
\mathrm{n}\end{array}$ & $\begin{array}{l}\text { Fly } \\
\text { Ash }\end{array}$ & $\begin{array}{c}\text { Sab } \\
\text { ut } \\
\text { Kel } \\
\text { apa }\end{array}$ & Air & $\begin{array}{c}\text { Seme } \\
n\end{array}$ & $\begin{array}{l}\text { Fly } \\
\text { ash }\end{array}$ & $\begin{array}{c}\text { Sabut } \\
\text { Kela } \\
\text { pa }\end{array}$ \\
\hline & & & & & 108,9 & & \\
\hline 1 & 100 & 0 & 0 & 14,73 & 7 & 0 & 0 \\
\hline 2 & 90 & 0 & 10 & 14,74 & 98,07 & 0 & 4,37 \\
\hline 3 & 80 & 0 & 20 & 14,75 & 87,18 & 0 & 8,73 \\
\hline 4 & 70 & 0 & 30 & 14,76 & 76,28 & 0 & 13,1 \\
\hline 5 & 90 & 5 & 5 & 14,77 & 98,07 & 4,23 & 2,18 \\
\hline 6 & 80 & 5 & 15 & 14,78 & 87,18 & 4,23 & 6,55 \\
\hline 7 & 80 & 10 & 10 & 14,79 & 87,18 & 8,46 & 4,37 \\
\hline 8 & 80 & 15 & 5 & 14,80 & 87,18 & 12,68 & 2,18 \\
\hline 9 & 70 & 5 & 25 & 14,81 & 76,28 & 4,23 & 10,91 \\
\hline 10 & 70 & 10 & 20 & 14,82 & 76,28 & 8,46 & 8,73 \\
\hline 11 & 70 & 15 & 15 & 14,83 & 76,28 & 12,68 & 6,55 \\
\hline 12 & 70 & 20 & 10 & 14,84 & 76,28 & 16,91 & 4,37 \\
\hline 13 & 70 & 25 & 5 & 14,85 & 76,28 & 21,14 & 2,18 \\
\hline
\end{tabular}

\section{Hasil dan Pembahasan}

Hasil kuat tekan dari komposisi pasta semen yang meliputi OPC, ASK dan FA dengan umur rencana 3 hari dan 7 hari ditunjukkan pada Tabel 6.

Tabel 6. Hasil Kuat Uji Tekan Pasta Semen pada umur 3 hari dan 7 hari

\begin{tabular}{clc}
\hline No. & \multicolumn{2}{l}{ Tegangan hancur kuat tekan $\left(\mathrm{Kg} / \mathrm{cm}^{2}\right)$} \\
\hline 1 & 3 hari & 7 hari \\
2 & 10,18 & 66,18 \\
3 & 10,18 & 15,27 \\
4 & 5,09 & 10,18 \\
5 & 5,09 & 15,27 \\
6 & 61,09 & 81,45 \\
7 & 40,11 & 78,77 \\
8 & 14,13 & 76,05 \\
9 & 11,12 & 67,91 \\
10 & 9,08 & 66,1 \\
11 & 5,09 & 61,08 \\
12 & 5,09 & 45,82 \\
13 & 5,09 & 15,27 \\
\hline
\end{tabular}

Dari hasil pengujian dapat dilihat bahwa komposisi semen $100 \%$ sebagai sampel no 1 yaitu variable control. Pasta semen memenuhi standar adalah jika dapat mereduksi penggunaan semen terbanyak namun juga tetap menpunyai karakteristik yang sama. Dari Tabel 6, dapat ditarik kesimpulan yang mendekati variabel kontrol adalah sampel komposisi no 9 dengan $70 \%$ semen, $5 \%$ fly ash, dan 25\% sabut kelapa.

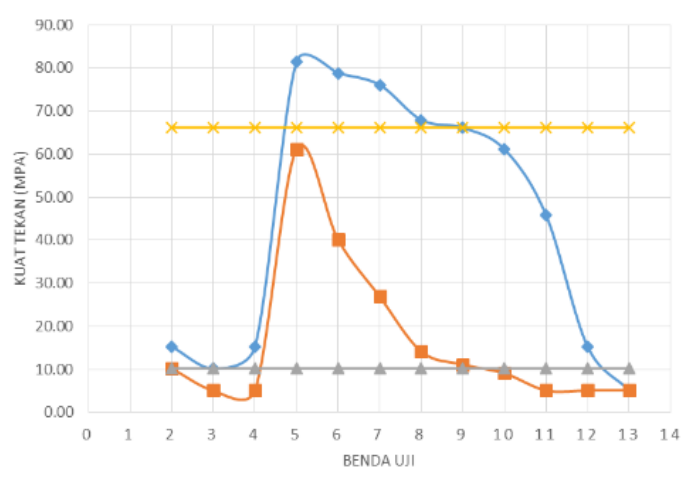

Gambar 3. Grafik Hubungan variasi benda uji pasta semen dengan korelasi kuat tekan dan jenis kompisisi

\section{Kesimpulan}

Hasil penelitian ini memberi kesimpulan bahwa komposisi optimum komposit limbah sabut kelapa dan fly ash berhasil mensubtitusi 30\% semen dengan komposisi: 25\% abu serabut kelapa dan 5\% fly ash.

\section{Daftar Pustaka}

ASTM-C618-03. (2003). Standard Specification for Coal Fly Ash and Raw or Calcined Natural Pozzolan for Use in Concrete. Philadelphia, USA.

Bayuaji, R., (2015). The Influence Of Microwave Incinerated Rice Husk Ash On Foamed Concrete Workability And Compressive Strength Using Taguchi Method. Jurnal Teknologi 75:1: 265-274.

Bayuaji, R., M. S. Darmawan, I. P. Rahardjo and N. A. Husin. (2011). 
Characterization of Pozzolanicity Bromo's Volcanic Ash International Seminar on Applied Technology, Science, and Arts (3rd APTECS), Surabaya.

Bayuaji, R. and M. F. Nuruddin. (2014). Influence of Microwave Incinerated Rice Husk Ash on Hydration of Foamed Concrete. Advances in Civil Engineering.

Kementan. (2005). Prospek dan Arah Pengembangan Agribisnis Kelapa.

Neville, A. M., (2010). Properties of Concrete (4th edn). Longman, London, Pearson.

Nuruddin, M. F. and R. Bayuaji. (2010). Sidoarjo mud: A potential cement replacement material. Civil Engineering Dimension 12.1: 18-22.

Van Oss, H. G. and A. C. Padovani. (2002). Cement manufacture and the environment-Part I: Chemistry and technology. Journal of Industrial Ecology 6(1): 89-106. 